\title{
Solubility Prediction of Drugs in Water-Polyethylene Glycol 400 Mixtures Using Jouyban-Acree Model
}

\author{
Abolghasem JouYBAN \\ Faculty of Pharmacy and Drug Applied Research Center, Tabriz University of Medical Sciences; Tabriz 51664, Iran. \\ Received July 4, 2006; accepted August 1, 2006
}

A numerical method is proposed for predicting solubility of drugs in water-PEG 400 mixtures based on the Jouyban-Acree cosolvency model. The accuracy of the proposed method is evaluated by computing mean percentage deviation (MPD) and compared with that of log-linear model of Yalkowsky. The overall MPDs of the Jouyban-Acree model and the most accurate version of Yalkowsky's model are $39.8( \pm 46.7) \%$ and $175.8( \pm 266.4) \%$, respectively, and the mean difference is statistically significant $(p<0.0005)$. The proposed method produces acceptable residual distribution and the probability of solubility prediction with residual log of solubility $<0.5$ unit is 0.86 . The applicability of the proposed method could be extended for predicting the solubility of drugs in water-PEG 400 mixtures at various temperatures. The impact of various $\log P$ values computed using different software is also studied and the results of ANOVA revealed that there are no significant differences between the accuracy of the predicted solubilities employing various $\log P$ values.

Key words solubility prediction; cosolvency modeling; water-PEG 400 mixture; log-linear; Jouyban-Acree

Solubilization of low soluble drug/drug candidate using various solubilization procedures is required in early stages of drug discovery studies and addition of a miscible cosolvent is the most common technique to increase solubility. In addition to experimental efforts to collect solubility data in mixed solvents, a number of models have been presented to calculate the solubility including the log-linear of Yalkowsky, ${ }^{1)}$ the extended Hildebrand solubility approach of Martin, ${ }^{2)}$ the Jouyban-Acree, ${ }^{3,4)}$ the phenomenological, ${ }^{5)}$ the modified Wilson, ${ }^{6}$ general single ${ }^{7)}$ and Ruckenstein and Shulgin ${ }^{8)}$ models. Most of the models have been reviewed in a recent paper and a unified version of the models has been proposed.9) Polyethylene glycol (PEG) 400 is the most common cosolvent in formulation of soft gelatin capsules, as examples, it has been used to formulate ethosuximide, bexarotene, etoposide, nifedipine, nimodipine and digoxin. ${ }^{10)}$ It has also been used in formulation of oral/injectable solutions as a solubilization agent. ${ }^{10}$

$$
\begin{aligned}
& \text { Computational Methods } \\
& \text { The algebraic mixing rule }{ }^{1)} \text { or log-linear model was expressed by: } \\
& \log X_{\mathrm{m}}=f_{\mathrm{c}} \log X_{\mathrm{c}}+f_{\mathrm{w}} \log X_{\mathrm{w}}
\end{aligned}
$$

where $X_{\mathrm{m}}$ is the solut'e solubility in water-cosolvent mixtures, $f_{\mathrm{c}}$ and $f_{\mathrm{w}}$ the volume fractions of cosolvent and water in the absence of the solute, $X_{\mathrm{c}}$ and $X_{\mathrm{w}}$ the solubilities in neat cosolvent and water, respectively. It is obvious that the $X$ values could be exprerssed in $\mathrm{g} / \mathrm{l}, \mathrm{mol} / \mathrm{l}$, mole fraction etc. By replac$\operatorname{ing} f_{\mathrm{w}}$ with $\left(1-f_{\mathrm{c}}\right)$, Eq. 1 could be re-written as:

$$
\begin{aligned}
& \log X_{\mathrm{m}}=\log X_{\mathrm{w}}+\left(\log X_{\mathrm{c}}-\log X_{\mathrm{w}}\right) f_{\mathrm{c}} \\
& \log X_{\mathrm{m}}=\text { intercept+slope } f_{\mathrm{c}} \text { or } \log X_{\mathrm{m}}=\log X_{\mathrm{w}}+\sigma f_{\mathrm{c}}
\end{aligned}
$$

In which $\sigma$ is the solubilization power of a cosolvent. The $\sigma$ was correlated to the octanol-water partition coefficient $(P)$ of the solute as ${ }^{11)}$ :

$$
\sigma=S_{0}+S_{1} \log P
$$

the regression parameters $S_{0}$ and $S_{1}$ are specific for the solvent and independent of the solutes. Eqs. 3 and 4 could be combined as:

$$
\log X_{\mathrm{m}}=\log X_{\mathrm{w}}+\left(S_{0}+S_{1} \log P\right) f_{\mathrm{c}}
$$

$$
\log X_{\mathrm{m}}-\log X_{\mathrm{w}}=S_{0} f_{\mathrm{c}}+S_{1} f_{\mathrm{c}} \log P
$$

In which $S_{0}$ and $S_{1}$ values were computed using a no-intercept least square analysis in this work. The previously reported $S_{0}$ and $S_{1}$ values were computed by regressing slope of the $\log$-linear model (i.e. $\sigma$ ) against $\log P$ of the solutes.

The log-linear model presents ideal mixing behaviour of the solutions and could be extended to the models possessing more constants representing the non-ideality of the observed solubility data. As it has been shown in a previous paper, ${ }^{11)}$ employing more model constants (curve-fitting parameters) provide more accurate correlation and obviously more accurate prediction. The Jouyban-Acree model is one of these models which provided the most accurate correlation among similar cosolvency models. ${ }^{11)}$ Its basic form for calculating a solute solubility in a water-cosolvent mixture is:

$$
\log X_{\mathrm{m}}=f_{\mathrm{c}} \log X_{\mathrm{c}}+f_{\mathrm{w}} \log X_{\mathrm{w}}+f_{\mathrm{c}} f_{\mathrm{w}} \sum_{i=0}^{2} A_{i}\left(f_{\mathrm{c}}-f_{\mathrm{w}}\right)^{i}
$$

where $A_{i}$ the solvent-solvent and solute-solvent interaction terms ${ }^{3)}$ computed using a no-intercept least square analysis. The model could be written as Eq. 8 to calculate the solubility of drugs in binary solvents at various temperatures ${ }^{12)}$.

$$
\log X_{\mathrm{m}, T}=f_{\mathrm{c}} \log X_{\mathrm{c}, T}+f_{\mathrm{w}} \log X_{\mathrm{w}, T}+f_{\mathrm{c}} f_{\mathrm{w}} \sum_{i=0}^{2} \frac{J_{i}\left(f_{\mathrm{c}}-f_{\mathrm{w}}\right)^{i}}{T}
$$

where $X_{\mathrm{m}, T}, X_{\mathrm{c}, T}$ and $X_{\mathrm{w}, T}$ are the solubility of the solute in solvent mixture, cosolvent and water in the absence of the solute at temperature $(T, \mathrm{~K})$ and $J_{i}$ is the model constant. By this extension, one is able to predict solubilities in mixed solvents at various temperatures which quite beneficial to pharmaceutical industry.

The mean percentage deviation (MPD) was used to check the accuracy of the prediction method and is calculated using Eq. 9:

$$
\operatorname{MPD}=\left(\frac{100}{N}\right)\left(\frac{\sum \mid \text { calculated }\left(X_{\mathrm{m}}\right)-\operatorname{observed}\left(X_{\mathrm{m}}\right) \mid}{\operatorname{observed}\left(X_{\mathrm{m}}\right)}\right)
$$

in which $N$ is the number of solubility data points.

\section{Results and Discussion}

Available experimental solubility data of drugs in waterPEG 400 mixtures expressed in mole per liter and g/l are collected from the literature. ${ }^{13,14)}$ The data sets containing $X_{\mathrm{c}}$ and $X_{\mathrm{w}}$ values are included in this study, since the Jouyban-Acree model requires these values as input data. Details 
Table 1. Details of Solubility Data of Drugs in Water-PEG 400 (Number of Data Points in Each Set Was 5), $\log P$ Values, and Mean Percentage Deviations for Eqs. $10-12$

\begin{tabular}{|c|c|c|c|c|}
\hline Name & $\log P^{a)}$ & Eq. 10 & Eq. 11 & Eq. 12 \\
\hline Acetazolamide & -0.30 & 13.7 & 37.6 & 39.2 \\
\hline Adenine & -0.10 & 6.9 & 90.8 & 49.4 \\
\hline Adenosine & -1.30 & 13.6 & 80.6 & 45.0 \\
\hline$p$-Aminobenzoic acid & 0.00 & 16.5 & 25.3 & 24.6 \\
\hline Aminopyrine & 0.80 & 38.9 & 797.7 & 707.0 \\
\hline Ampicillin & 1.40 & 37.9 & 106543.9 & 118929.7 \\
\hline Aspirin & 1.20 & 13.4 & 75.4 & 78.3 \\
\hline Atropine & 1.50 & 19.1 & 681.2 & 791.5 \\
\hline Azathioprine & 0.90 & 35.4 & 13.3 & 13.3 \\
\hline Benzamide & 0.70 & 24.9 & 494.5 & 417.3 \\
\hline Benzoic acid & 1.90 & 12.5 & 92.0 & 130.0 \\
\hline Bumetanide & 2.80 & 50.1 & 50.4 & 45.2 \\
\hline Butamben & 3.60 & 17.9 & 30.6 & 44.2 \\
\hline Butylparaben & 3.50 & 15.2 & 36.0 & 58.5 \\
\hline Carbamazepine & 2.70 & 27.0 & 103.1 & 175.7 \\
\hline Chloramphenicol & 1.00 & 27.0 & 42.6 & 40.2 \\
\hline Chlorthalidone & -0.70 & 32.1 & 75.4 & 76.6 \\
\hline Chlorzoxazone & 2.20 & 23.5 & 36.8 & 60.0 \\
\hline Cimetidine & 0.40 & 20.2 & 629.6 & 475.9 \\
\hline Clofazimine & 7.50 & 69.0 & 470.9 & 4900.9 \\
\hline Cortisone & 1.20 & 41.0 & 102.1 & 106.5 \\
\hline Dapsone & 0.90 & 50.1 & 67.7 & 68.5 \\
\hline Deoxycorticosterone & 3.40 & 56.6 & 170.1 & 420.6 \\
\hline Dexamethasone & 2.10 & 10.8 & 41.3 & 53.5 \\
\hline Diflunisal & 4.30 & 22.4 & 247.9 & 952.3 \\
\hline Diosgenin & 5.70 & 1091.6 & 5848.6 & 21375.9 \\
\hline Disopyramide & 2.90 & 200.6 & 1861.1 & 3345.2 \\
\hline Equilin & 3.50 & 11.5 & 46.7 & 25.4 \\
\hline Estradiol-17-alpha & 4.10 & 23.8 & 50.2 & 59.2 \\
\hline Estriol & 2.90 & 21.8 & 57.0 & 91.4 \\
\hline Estrone & 3.70 & 6.7 & 32.1 & 63.7 \\
\hline Ethylparaben & 2.40 & 17.6 & 49.7 & 67.4 \\
\hline Fenbufen & 3.00 & 87.0 & 35.7 & 70.8 \\
\hline Flufenamic acid & 5.60 & 19.2 & 461.5 & 2628.3 \\
\hline Flurbiprofen & 4.10 & 34.7 & 36.0 & 47.6 \\
\hline Glafenine & 3.90 & 15.8 & 59.8 & 210.2 \\
\hline Griseofulvin & 2.40 & 47.5 & 78.1 & 77.5 \\
\hline Guaifenesin & 0.60 & 17.2 & 293.7 & 237.2 \\
\hline Guanine & -0.9 & 47.0 & 362.6 & 160.1 \\
\hline Hydrochlorothiazide & -0.10 & 39.7 & 63.0 & 68.0 \\
\hline Hydrocortisone & 1.40 & 10.4 & 239.0 & 271.4 \\
\hline Hydroflumethiazide & 0.50 & 29.9 & 50.3 & 46.4 \\
\hline Ibuprofen & 3.70 & 51.8 & 38.1 & 59.6 \\
\hline Indapamide & 2.10 & 19.3 & 53.4 & 47.1 \\
\hline Indoprofen & 1.70 & 25.0 & 51.2 & 47.9 \\
\hline Iopanoic acid & 5.20 & 23.7 & 52.6 & 32.8 \\
\hline Ketoprofen & 2.80 & 20.2 & 45.8 & 35.3 \\
\hline Mefenamic acid & 5.30 & 59.0 & 57.1 & 340.1 \\
\hline Methylparaben & 1.90 & 43.7 & 422.1 & 575.2 \\
\hline Metronidazole & 0.00 & 50.6 & 850.6 & 562.5 \\
\hline Minoxidil & -1.50 & 32.7 & 74.6 & 35.2 \\
\hline Nadolol & 1.30 & 56.2 & 4950.0 & 5293.7 \\
\hline Nalidixic acid & 0.20 & 220.1 & 141.1 & 102.1 \\
\hline Naphthalene & 3.40 & 37.0 & 38.9 & 13.9 \\
\hline 2-Naphthol & 2.70 & 37.0 & 154.3 & 288.8 \\
\hline Naproxen & 3.00 & 9.6 & 52.4 & 36.0 \\
\hline Norethisterone & 3.40 & 51.7 & 42.6 & 135.8 \\
\hline Norfloxacin & 1.50 & 269.3 & 1118.6 & 1263.9 \\
\hline Paracetamol & 0.30 & 17.0 & 78.8 & 63.3 \\
\hline Phenacetin & 1.60 & 20.6 & 63.6 & 85.8 \\
\hline Phenolphthalein & 3.30 & 51.5 & 72.1 & 63.3 \\
\hline Phenylbutazone & 3.50 & 174.8 & 61.0 & 161.2 \\
\hline Prednisolone & 1.70 & 15.6 & 46.5 & 62.7 \\
\hline Primidone & -1.00 & 40.6 & 30.6 & 35.9 \\
\hline Progesterone & 4.00 & 133.7 & 390.9 & 1032.9 \\
\hline Propylparaben & 2.90 & 18.3 & 48.0 & 73.1 \\
\hline Quinidine & 3.40 & 77.3 & 1656.5 & 3767.8 \\
\hline
\end{tabular}

Table 1. (Continued)

\begin{tabular}{lrrrr}
\hline \hline \multicolumn{1}{c}{ Name } & $\log P^{a)}$ & Eq. 10 & Eq. 11 & Eq. 12 \\
\hline Quinine & 3.40 & 77.4 & 651.7 & 1467.8 \\
Salicylamide & 1.40 & 5.3 & 32.0 & 33.2 \\
Salicylic acid & 2.10 & 9.0 & 47.9 & 65.7 \\
Sulfadiazine & -0.10 & 7.3 & 66.0 & 68.6 \\
Sulfamethazine & 0.80 & 16.2 & 42.8 & 40.4 \\
Sulfamethoxazole & 0.90 & 23.6 & 68.3 & 68.8 \\
Sulfanilamide & -0.70 & 31.7 & 54.4 & 32.1 \\
Sulfathiazole & 0.30 & 12.6 & 47.5 & 52.5 \\
Tenoxicam & -0.30 & 31.1 & 58.5 & 63.3 \\
Thiamphenicol & -0.30 & 34.4 & 17.8 & 31.8 \\
Triamcinolone & 1.10 & 6.0 & 42.8 & 42.6 \\
1,2,3-Trichlorobenzene & 3.80 & 23.9 & 75.3 & 72.1 \\
Trimethoprim & 0.80 & 19.0 & 137.9 & 120.7 \\
Xanthine & -0.60 & 3.5 & 220.7 & 95.5 \\
\multicolumn{1}{c}{ Overall MPD: } & & 52.8 & 1639.7 & 2148.4 \\
Overall MPD after one & & 39.8 & 328.4 & 688.6 \\
excluded data set: & & & & \\
\hline
\end{tabular}

a) $\log P$ values taken from Rytting et al. ${ }^{16)}$ which are calculated using ACD software.

Table 2. The Model Constants of Log-Linear of Yalkowsky Using 79 Data Sets (Excluded Set Are Ampicillin and Diosgenin) and Various $\log P$ Values

\begin{tabular}{lccc}
\hline \hline \multicolumn{1}{c}{$\log P$ values } & Ref. & $S_{0}( \pm$ S.E. $)$ & $S_{1}( \pm$ S.E. $)$ \\
\hline $\left.\mathrm{ACD}^{a}\right)$ & 16 & $1.383( \pm 0.073)$ & $0.577( \pm 0.028)$ \\
KowWin $^{\circledR}$ & 17 & $1.608( \pm 0.082)$ & $0.480( \pm 0.032)$ \\
$\left.\mathrm{ACD}^{b}\right)$ & 17 & $1.281( \pm 0.079)$ & $0.608( \pm 0.031)$ \\
$\mathrm{ClogP}$ & 17 & $1.341( \pm 0.072)$ & $0.629( \pm 0.029)$ \\
Experimental & 17 & $1.320( \pm 0.079)$ & $0.616( \pm 0.033)$ \\
\multicolumn{1}{c}{-} & 16 & $1.45( \pm 0.15)$ & $0.57( \pm 0.06)$ \\
& 15 & $1.26( \pm 0.22)$ & $0.74( \pm 0.07)$ \\
\hline
\end{tabular}

a) $\log P$ values taken from Rytting et al. ${ }^{16)}$ b) $\log P$ values taken from Machatha and Yalkowsky. ${ }^{17)}$

of data, MPD values and the overall MPD $( \pm$ S.D. $)$ are listed in Table 1. The data is fitted to Eq. 8, and the trained model is:

$$
\begin{aligned}
\log X_{\mathrm{m}, T}= & f_{\mathrm{c}} \log X_{\mathrm{c}, T}+f_{\mathrm{w}} \log X_{\mathrm{w}, T} \\
& +f_{\mathrm{c}} f_{\mathrm{w}}\left[\frac{394.82}{T}-\frac{355.28\left(f_{\mathrm{c}}-f_{\mathrm{w}}\right)}{T}+\frac{388.89\left(f_{\mathrm{c}}-f_{\mathrm{w}}\right)^{2}}{T}\right]
\end{aligned}
$$

The prediction capability of Eq. 10 is compared with those of the log-linear model of Yalkowsky using reported model constants:

$$
\log X_{\mathrm{m}}=\log X_{\mathrm{w}}+\left(1.26+0.74 S_{1} \log P\right) f_{\mathrm{c}}
$$

by Millard el al. ${ }^{15)}$ and

$$
\log X_{\mathrm{m}}=\log X_{\mathrm{w}}+(1.45+0.57 \log P) f_{\mathrm{c}}
$$

by Rytting et al. ${ }^{16)}$

The maximum MPD value for Eq. 10 is $1091.6 \%$ (for diosgenin). The data set of diosgenin in water-PEG 400 was questionable, since the authors reported -2.618 in Table 1 of the reference ${ }^{13)}$ for $\log$ of aqueous solubility of diosgenin against -5.075 in Table 2 of the same reference. ${ }^{13)}$ In addition to the numerical value of aqueous solubility of diosgenin, the solubility behavior of the solute in water-PEG 400 mixture $(75: 25)$ was also unusual, i.e. the solubility decreased with $25 \%$ cosolvent addition and then increased with 
Table 3. Various $\log P$ Values and the Mean Percentage Deviations (MPDs) of the Log-Linear Model Using $\log P \mathrm{~s}$

\begin{tabular}{|c|c|c|c|c|c|c|c|c|c|c|}
\hline \multirow{2}{*}{ Solute } & \multicolumn{5}{|c|}{$\log P$ values } & \multicolumn{5}{|c|}{ MPD values using different $\log P \mathrm{~s}$} \\
\hline & $\mathrm{ACD}^{a)}$ & $\mathrm{ACD}^{b)}$ & KowWin $^{(B b)}$ & $C \log \mathrm{P}^{b)}$ & $\log P_{\exp }^{b)}$ & $\mathrm{ACD}^{a)}$ & $\mathrm{ACD}^{b)}$ & KowWin $^{(B b)}$ & $\operatorname{Clog} \mathrm{P}^{b)}$ & $\log P_{\text {exp }}^{b)}$ \\
\hline Acetazolamide & -0.30 & -0.26 & -0.73 & -1.25 & -0.26 & 35.5 & 33.6 & 36.9 & 58.9 & 34.2 \\
\hline Adenine & -0.10 & -0.03 & -0.73 & -0.29 & -0.11 & 72.9 & 59.2 & 58.4 & 47.4 & 57.4 \\
\hline Adenosine & -1.30 & -1.02 & -1.38 & -2.27 & -1.12 & 70.7 & 74.0 & 145.8 & 46.9 & 70.3 \\
\hline$p$-Aminobenzoic acid & 0.00 & 0.83 & 0.96 & 0.98 & 0.73 & 22.7 & 51.8 & 127.9 & 90.1 & 49.0 \\
\hline Aminopyrine & 0.80 & 0.76 & 0.60 & 0.57 & 0.90 & 695.9 & 552.5 & 780.1 & 500.3 & 742.4 \\
\hline Aspirin & 1.20 & 1.20 & 1.13 & 1.02 & 1.25 & 64.2 & 53.5 & 78.8 & 49.3 & 66.7 \\
\hline Atropine & 1.50 & 1.50 & 1.91 & 1.32 & 1.82 & 597.6 & 524.5 & 1129.4 & 498.0 & 930.5 \\
\hline Azathioprine & 0.90 & 0.90 & -0.09 & 0.01 & 0.10 & 13.4 & 19.0 & 37.2 & 47.3 & 46.0 \\
\hline Benzamide & 0.70 & 0.70 & 0.74 & 0.65 & 0.65 & 426.7 & 353.3 & 647.0 & 390.3 & 364.4 \\
\hline Benzoic acid & 1.90 & 1.90 & 1.87 & 1.88 & 1.87 & 83.0 & 76.6 & 87.2 & 90.2 & 81.7 \\
\hline Bumetanide & 2.80 & 2.78 & 2.57 & 3.36 & -0.30 & 50.9 & 51.2 & 52.0 & 41.3 & 70.2 \\
\hline Butamben & 3.60 & 3.60 & 2.78 & 2.98 & 3.02 & 33.5 & 32.8 & 56.3 & 46.8 & 48.2 \\
\hline Butylparaben & 3.50 & 3.50 & 3.47 & 3.57 & 3.57 & 34.9 & 35.0 & 41.7 & 40.9 & 38.3 \\
\hline Carbamazepine & 2.70 & 2.70 & 2.25 & 1.98 & 2.32 & 94.8 & 91.9 & 64.3 & 56.7 & 69.9 \\
\hline Chloramphenicol & 1.00 & 1.00 & 0.92 & 1.28 & 1.14 & 37.4 & 32.9 & 46.5 & 64.9 & 42.9 \\
\hline Chlorthalidone & -0.70 & -0.74 & 1.59 & 0.45 & $-^{c}$ & 75.7 & 76.3 & 51.2 & 70.9 & $-^{c}$ \\
\hline Chlorzoxazone & 2.20 & 2.29 & 1.99 & 1.87 & - $^{c}$ & 33.3 & 34.7 & 28.3 & 26.1 & $-^{c)}$ \\
\hline Cimetidine & 0.40 & 0.40 & 0.57 & 0.35 & 0.47 & 544.2 & 441.8 & 995.6 & 481.6 & 537.7 \\
\hline Clofazimine & 7.50 & 7.50 & 7.55 & 6.69 & 7.48 & 456.0 & 604.2 & 165.8 & 322.8 & 723.3 \\
\hline Cortisone & 1.20 & 1.20 & 1.81 & 1.30 & 1.47 & 85.1 & 68.1 & 253.8 & 109.9 & 132.9 \\
\hline Dapsone & 0.90 & 0.90 & 0.77 & 0.89 & 0.97 & 69.0 & 70.4 & 67.3 & 69.0 & 68.7 \\
\hline Deoxycorticosterone & 3.40 & 3.40 & 3.12 & 3.25 & 2.88 & 152.2 & 153.7 & 76.3 & 168.5 & 73.3 \\
\hline Dexamethasone & 2.10 & 2.10 & 1.72 & 1.75 & 1.89 & 38.6 & 36.9 & 32.7 & 32.9 & 34.2 \\
\hline Diflunisal & 4.30 & 4.30 & 4.41 & 4.39 & 3.56 & 226.1 & 244.7 & 164.8 & 414.8 & 107.1 \\
\hline Disopyramide & 2.90 & 2.90 & 2.96 & 2.58 & 2.65 & 1702.9 & 1664.9 & 1615.1 & 1427.8 & 1397.2 \\
\hline Equilin & 3.50 & 3.53 & -2.81 & 2.90 & $-^{c)}$ & 48.5 & 47.4 & 77.9 & 56.6 & —c) \\
\hline Estradiol-17-alpha & 4.10 & 4.10 & 3.94 & 3.78 & 3.86 & 52.0 & 50.8 & 60.8 & 53.3 & 54.2 \\
\hline Estriol & 2.90 & 2.90 & 2.81 & 3.20 & 2.45 & 53.8 & 53.1 & 48.2 & 83.2 & 42.9 \\
\hline Estrone & 3.70 & 3.70 & 3.43 & 3.38 & 2.95 & 31.0 & 31.3 & 37.4 & 29.8 & 43.9 \\
\hline Ethylparaben & 2.40 & 2.40 & 2.49 & 2.51 & 2.47 & 46.9 & 45.6 & 48.8 & 56.6 & 51.1 \\
\hline Fenbufen & 3.00 & 3.00 & 3.18 & 3.14 & 3.20 & 34.2 & 34.2 & 34.0 & 50.5 & 47.9 \\
\hline Flufenamic acid & 5.60 & 5.60 & 5.15 & 4.88 & 4.32 & 431.5 & 512.8 & 102.8 & 260.6 & 83.2 \\
\hline Flurbiprofen & 4.10 & 4.10 & 3.81 & 3.75 & 4.16 & 37.3 & 36.5 & 48.3 & 38.7 & 32.4 \\
\hline Glafenine & 3.90 & 3.49 & 0.42 & 3.04 & -c) $^{c}$ & 56.5 & 43.4 & 74.2 & 38.8 & -c) \\
\hline Griseofulvin & 2.40 & 2.40 & 1.92 & 1.75 & 2.18 & 78.3 & 78.3 & 78.7 & 78.8 & 78.5 \\
\hline Guaifenesin & 0.60 & 0.57 & -1.05 & 0.10 & c) & 252.1 & 197.4 & 62.0 & 114.5 & $-^{c)}$ \\
\hline Guanine & -0.90 & -0.98 & -1.05 & -1.28 & -0.94 & 307.2 & 200.9 & 526.5 & 137.7 & 229.9 \\
\hline Hydrochlorothiazide & -0.10 & -0.07 & -0.07 & -0.40 & -0.07 & 64.9 & 66.9 & 56.6 & 69.7 & 66.1 \\
\hline Hydrocortisone & 1.40 & 1.40 & 1.62 & 1.70 & 1.65 & 204.7 & 173.4 & 341.5 & 363.2 & 300.9 \\
\hline Hydroflumethiazide & 0.50 & 0.50 & 0.22 & -0.25 & 0.36 & 47.8 & 47.0 & 49.4 & 63.3 & 49.4 \\
\hline Ibuprofen & 3.70 & 3.70 & 3.79 & 3.68 & 3.50 & 38.8 & 38.6 & 44.0 & 36.0 & 41.3 \\
\hline Indapamide & 2.10 & 2.09 & 5.78 & 2.94 & -c) $^{c}$ & 55.0 & 56.3 & 421.2 & 35.6 & -c) $^{c}$ \\
\hline Indoprofen & 1.70 & 2.77 & 2.32 & 2.74 & 2.77 & 52.9 & 26.9 & 39.3 & 23.5 & 23.7 \\
\hline Iopanoic acid & 5.20 & 4.19 & 3.00 & 4.89 & $-^{c}$ & 53.6 & 65.3 & 72.4 & 52.6 & $-^{c}$ \\
\hline Ketoprofen & 2.80 & 2.80 & 3.00 & 2.76 & 3.12 & 48.0 & 48.6 & 45.8 & 44.4 & 34.9 \\
\hline Mefenamic acid & 5.30 & 5.30 & 5.28 & 4.94 & 4.29 & 51.7 & 63.3 & 28.0 & 52.8 & 32.5 \\
\hline Methylparaben & 1.90 & 1.86 & 2.00 & 1.99 & 1.96 & 372.7 & 322.6 & 457.7 & 484.5 & 415.9 \\
\hline Metronidazole & 0.00 & -0.01 & 0.00 & -0.46 & -0.02 & 736.4 & 580.9 & 1195.7 & 353.7 & 623.8 \\
\hline Minoxidil & -1.50 & 0.69 & 1.35 & 0.48 & 1.33 & 61.9 & 976.0 & 3400.7 & 856.5 & 2617.3 \\
\hline Nadolol & 1.30 & 1.29 & 1.17 & 0.38 & 0.71 & 4369.9 & 3772.7 & 4725.1 & 1333.5 & 1945.7 \\
\hline Nalidixic acid & 0.20 & 1.00 & 1.64 & 1.32 & 1.50 & 123.7 & 260.8 & 644.1 & 432.4 & 491.7 \\
\hline Naphthalene & 3.40 & 3.35 & 3.17 & 3.32 & 3.30 & 41.2 & 42.6 & 50.6 & 36.6 & 40.8 \\
\hline 2-Naphthol & 2.70 & 2.70 & 2.69 & 2.65 & 2.78 & 140.7 & 136.1 & 130.3 & 161.0 & 170.5 \\
\hline Naproxen & 3.00 & 3.00 & 3.10 & 2.82 & 3.26 & 54.1 & 54.4 & 54.8 & 54.1 & 45.0 \\
\hline Norethisterone & 3.40 & 3.38 & 2.99 & 2.78 & 2.97 & 36.0 & 34.7 & 21.0 & 18.9 & 20.3 \\
\hline Norfloxacin & 1.50 & 1.48 & -0.31 & -0.99 & -1.26 & 1006.4 & 885.7 & 215.4 & 43.1 & 28.2 \\
\hline Paracetamol & 0.30 & 0.34 & 0.27 & 0.49 & 0.48 & 70.9 & 63.8 & 103.0 & 82.8 & 78.1 \\
\hline Phenacetin & 1.60 & 1.60 & 1.67 & 1.77 & 1.57 & 50.4 & 40.4 & 76.0 & 88.8 & 46.5 \\
\hline Phenolphthalein & 3.30 & 2.63 & 3.06 & 2.63 & 2.41 & 72.8 & 76.6 & 75.2 & 75.9 & 77.1 \\
\hline Phenylbutazone & 3.50 & 3.16 & 3.52 & 3.38 & 3.23 & 54.5 & 44.8 & 46.9 & 64.7 & 47.7 \\
\hline Prednisolone & 1.70 & 1.49 & 1.40 & 1.38 & 1.59 & 40.2 & 31.3 & 35.1 & 32.1 & 36.0 \\
\hline Primidone & -1.00 & 0.40 & 0.73 & 0.88 & 0.91 & 27.8 & 160.9 & 451.7 & 390.9 & 378.3 \\
\hline Progesterone & 4.00 & 4.00 & 3.67 & 3.77 & 3.87 & 361.2 & 378.1 & 184.4 & 376.4 & 370.2 \\
\hline Propylparaben & 2.90 & 2.90 & 2.98 & 3.04 & 3.04 & 45.7 & 45.1 & 44.8 & 57.8 & 53.3 \\
\hline Quinidine & 3.40 & 3.40 & 3.29 & 2.79 & 2.36 & 1512.8 & 1524.8 & 1087.2 & 898.2 & 458.4 \\
\hline Quinine & 3.40 & 3.44 & 3.29 & 2.79 & 2.36 & 595.1 & 631.3 & 426.1 & 350.1 & 169.8 \\
\hline Salicylamide & 1.40 & 1.40 & 1.03 & 1.28 & 1.28 & 30.8 & 29.8 & 29.6 & 30.0 & 29.5 \\
\hline
\end{tabular}


Table 3. (Continued)

\begin{tabular}{|c|c|c|c|c|c|c|c|c|c|c|}
\hline \multirow{2}{*}{ Solute } & \multicolumn{5}{|c|}{$\log P$ values } & \multicolumn{5}{|c|}{ MPD values using different $\log P$ s } \\
\hline & $\left.\mathrm{ACD}^{a}\right)$ & $\mathrm{ACD}^{b)}$ & KowWin $^{\circledR b)}$ & $\mathrm{Clog} \mathrm{P}^{b)}$ & $\log P_{\exp }^{b)}$ & $\left.\mathrm{ACD}^{a}\right)$ & $\mathrm{ACD}^{b)}$ & KowWin $^{\circledR b)}$ & $\mathrm{Clog} \mathrm{P}^{b)}$ & $\log P_{\exp }^{b)}$ \\
\hline Salicylic acid & 2.10 & 2.06 & 2.24 & 2.19 & 2.24 & 44.3 & 40.8 & 50.7 & 53.8 & 52.1 \\
\hline Sulfadiazine & -0.10 & -0.12 & -0.34 & -0.09 & -0.07 & 66.9 & 68.4 & 65.2 & 67.4 & 67.6 \\
\hline Sulfamethazine & 0.80 & 0.80 & 0.76 & 1.07 & 0.28 & 40.1 & 37.3 & 47.4 & 53.0 & 38.6 \\
\hline Sulfamethoxazole & 0.90 & 0.90 & 0.48 & 0.55 & 0.89 & 69.1 & 70.1 & 69.9 & 71.5 & 69.6 \\
\hline Sulfanilamide & -0.70 & -0.72 & -0.55 & -0.57 & -0.70 & 45.4 & 33.7 & 111.4 & 45.8 & 35.8 \\
\hline Sulfathiazole & 0.30 & 0.30 & 0.72 & 0.72 & 0.05 & 49.9 & 53.1 & 29.4 & 39.4 & 56.3 \\
\hline Tenoxicam & -0.30 & 1.52 & 2.40 & 1.61 & 0.81 & 60.1 & 16.0 & 94.7 & 17.0 & 38.9 \\
\hline Thiamphenicol & -0.30 & -0.27 & -0.33 & -0.10 & -0.27 & 22.0 & 26.8 & 21.5 & 17.9 & 25.0 \\
\hline Triamcinolone & 1.10 & 0.83 & 0.96 & 0.67 & 1.16 & 39.9 & 32.6 & 42.3 & 32.1 & 40.6 \\
\hline 1,2,3-Trichlorobenzene & 3.80 & 4.27 & 3.81 & 4.04 & 4.09 & 75.5 & 73.7 & 76.0 & 73.7 & 74.0 \\
\hline Trimethoprim & 0.80 & 0.80 & 0.73 & 0.88 & 0.91 & 118.7 & 97.7 & 156.8 & 134.0 & 129.4 \\
\hline Xanthine & -0.60 & -0.81 & -1.15 & -0.70 & -0.73 & 181.9 & 87.3 & 191.4 & 123.8 & 112.9 \\
\hline Overall MPD: & & & & & & 232.7 & 228.9 & 298.1 & 175.8 & 220.6 \\
\hline
\end{tabular}
ence. $^{17)}$

a) $\log P$ values taken from Rytting et al. ${ }^{16)} \quad$ b) $\log P$ values taken from Machatha and Yalkowsky. ${ }^{17)} \quad c$ ) Experimental $\log P$ values have not been reported in the refer-

further increase in PEG 400 concentration in the mixture. We assumed that this was due to a typographical error and therefore, this data set was excluded from the computations. The overall MPD ( \pm S.D.) for 80 data sets is $39.8( \pm 46.7)$. The maximum MPDs for Eqs. 11 and 12 are 106543.6 and $118929.7 \%$ (both for ampicillin). The numerical value of $\log P$ of ampicillin using ACD software reported by Rytting et $a .^{16)}$ is 1.4 whereas the corresponding values using $\mathrm{KowWin}^{\circledR}, \mathrm{Clog} \mathrm{P}^{\circledR}$ and the experimentally obtained values were $-0.88,-1.20$ and -0.81 , respectively. ${ }^{17)}$ To compare the results of the models using similar conditions, MPD of ampicillin was excluded from the comparison. The overall MPDs ( \pm S.D.s) of Eqs. 11 and 12 were 328.4 ( \pm 884.9$)$ and $688.6( \pm 2546.0) \%$, respectively which are significantly $(p<0.02)$ higher than overall MPD (39.8) of Eq. 10.

Machatha and Yalkowsky ${ }^{17)}$ compared the accuracy of the $\log P$ values computed by three software, i.e. $C \log \mathrm{P}^{\circledR}$, ACD $\log P$ and KowWin ${ }^{\circledR}$ with the corresponding experimental $\log P$ values in octanol/water system and found that the $C \log \mathrm{P}^{\circledR}$ provided the most accurate $\log P$ values among the other software. In this work, the impact of the various $\log P$ values on the prediction capability of the log-linear model was studied using data of drugs in water-PEG 400 mixtures. To keep a similar comparison conditions, all available $\log P$ data was used to train Eq. 6 and the back-calculated solubilities were used to compute MPDs. Data sets of diosgenin and ampicillin was excluded from this study. Table 2 showed the constants of the log-linear model and Table 3 listed the numerical values of various $\log P$ values and the MPDs for 79 studied solubility data sets. The $\log P$ values computed using ACD software reported by Rytting et al. ${ }^{16)}$ and Machatha and Yalkowsky ${ }^{17}$ are used to train separate models. There were a number of discrepancies between reported $\log P \mathrm{~s}$, as examples see $\log P \mathrm{~s}$ of $p$-aminobenzoic acid, indoprofen, minoxidil and nalidixic acid in Table 3. These variations are reflected in different MPD values for the drugs. However, the mean difference of MPDs for two sets of $\log P_{\mathrm{S}}$ is not statistically significant (paired $t$-test, $p>0.80$ ). In addition, the overall MPD differences of various $\log P \mathrm{~S}$ were examined using one-way ANOVA and the results revealed that there is no significant differences $(p>0.68)$ which means that one could use $\log P$ s computed using various soft- ware and/or experimental $\log P$ values to predict solubility by the log-linear model.

Rytting et al. ${ }^{16)}$ proposed a quantitative structure property relationship (QSPR) to compute drug solubility in each solvent composition of water-PEG 400 mixtures. The general form of the QSPR model was:

$$
\log X_{\mathrm{m}}=c_{0}+c_{1} \mathrm{MW}+c_{2} V_{\mathrm{m}}+c_{3} \mathrm{RB}+c_{4} \mathrm{HBA}+c_{5} \mathrm{HBD}+c_{6} \mathrm{RD}+c_{7} D_{\mathrm{m}}
$$

Where $\mathrm{MW}$ is the molecular weight $(\mathrm{g} / \mathrm{mol}), V_{\mathrm{m}}$ the molecular volume $\left(\AA^{3}\right)$, RB the number of rotatable bonds, HBA the number of hydrogen-bond acceptors, HBD the number of hydrogen bond donors, RG the radius of gyration $(\AA), D_{\mathrm{m}}$ the molecular density (ratio of molecular weight to volume) and $c_{0}-c_{7}$ are the model constants. ${ }^{16}$ ) The authors trained the model using two subsets for each solvent composition and reported the accuracy of the predictions using residuals in $\log$ units sorted in 5 subgroups. To compare the accuracy of the proposed model and the log-linear model using ACD and $\mathrm{C} \log \mathrm{P}$ data, the residuals in $\log$ units were computed and the results listed in Table 4. Relatively similar residual distributions are observed for ACD data (both results taken from a previous paper ${ }^{16)}$ and computed in this work) and ClogP data by using log-linear model. The order of the favored residual distributions could be presented as Jouyban-Acree $>\log$-linear $>$ QSPR model. The overall relative frequency of residuals for predicted solubilities in water-PEG 400 mixtures is shown in Fig. 1 confirming the same order. The probability of solubility prediction with $\log$ residual of $<0.5$ for Jouyban-Acree, best version of the log-linear and QSPR models are $0.86,0.68$ and 0.54 , respectively. The corresponding probabilities for $\log$ residual of $<1.0$ are $0.97,0.80$ and 0.78 .

To show the applicability of the proposed method for predicting solubility of drugs in water-PEG 400 mixtures at various temperatures, the solubility data of paracetamol taken from a reference ${ }^{14)}$ were predicted using Eq. 10. Figure 2 shows the predicted and experimental solubilities of paracetamol in water-PEG 400 mixtures at $30^{\circ} \mathrm{C}$. As it has been shown, good agreement has been found between predicted and experimental solubilities and the MPD was $12.8 \%$.

In using the proposed prediction method, one should consider that: 
Table 4. Residual $\log X_{\mathrm{m}}$ for Various Models Studied in Five Subgroups Reported by Rytting et al. ${ }^{16)}$

\begin{tabular}{|c|c|c|c|c|c|c|c|c|c|c|}
\hline & \multicolumn{2}{|c|}{$<0.5$} & \multicolumn{2}{|c|}{$0.5-1.0$} & \multicolumn{2}{|c|}{$1.0-1.5$} & \multicolumn{2}{|c|}{$1.5-2.0$} & \multicolumn{2}{|c|}{$>2.0$} \\
\hline & $\%$ & $\mathrm{~N}$ & $\%$ & $\mathrm{~N}$ & $\%$ & $\mathrm{~N}$ & $\%$ & $\mathrm{~N}$ & $\%$ & $\mathrm{~N}$ \\
\hline \multicolumn{11}{|c|}{ QSPR (Rytting model ${ }^{16)}$ ) } \\
\hline $25 \%$ PEG 400 & 47.7 & 18 & 31.6 & 12 & 7.9 & 3 & 5.3 & 2 & 7.9 & 3 \\
\hline $50 \%$ PEG 400 & 63.2 & 24 & 15.8 & 6 & 13.2 & 5 & 5.3 & 2 & 2.6 & 1 \\
\hline $75 \%$ PEG 400 & 52.6 & 20 & 23.7 & 9 & 10.5 & 4 & 13.2 & 5 & 0.0 & 0 \\
\hline \multicolumn{11}{|c|}{ Log-linear (reported results ${ }^{16)}$ ) } \\
\hline $25 \%$ PEG 400 & 76.3 & 29 & 15.8 & 6 & 5.3 & 2 & 2.6 & 1 & 0.0 & 0 \\
\hline $50 \%$ PEG 400 & 57.9 & 22 & 34.2 & 13 & 5.3 & 2 & 2.6 & 1 & 0.0 & 0 \\
\hline $75 \%$ PEG 400 & 36.8 & 14 & 31.6 & 12 & 21.1 & 8 & 5.3 & 2 & 5.3 & 2 \\
\hline \multicolumn{11}{|c|}{ Log-linear (ACD Rytting data) } \\
\hline $25 \%$ PEG 400 & 53.1 & 43 & 24.7 & 20 & 13.6 & 11 & 4.9 & 4 & 3.7 & 3 \\
\hline $50 \%$ PEG 400 & 65.4 & 53 & 19.8 & 16 & 8.6 & 7 & 6.2 & 5 & 0.0 & 0 \\
\hline $75 \%$ PEG 400 & 80.2 & 65 & 14.8 & 12 & 3.7 & 3 & 1.2 & 1 & 0.0 & 0 \\
\hline \multicolumn{11}{|c|}{ Log-linear (ClogP data) } \\
\hline $25 \%$ PEG 400 & 53.8 & 43 & 32.5 & 26 & 11.3 & 9 & 1.3 & 1 & 1.3 & 1 \\
\hline $50 \%$ PEG 400 & 72.5 & 58 & 15.0 & 12 & 10.0 & 8 & 1.3 & 1 & 1.3 & 1 \\
\hline $75 \%$ PEG 400 & 78.8 & 63 & 17.5 & 14 & 2.5 & 2 & 1.3 & 1 & 0.0 & 0 \\
\hline \multicolumn{11}{|c|}{ Jouyban-Acree model } \\
\hline $25 \%$ PEG 400 & 88.9 & 72 & 8.6 & 7 & 2.5 & 2 & 0.0 & 0 & 0.0 & 0 \\
\hline $50 \%$ PEG 400 & 80.2 & 65 & 17.3 & 14 & 2.5 & 2 & 0.0 & 0 & 0.0 & 0 \\
\hline $75 \%$ PEG 400 & 88.9 & 72 & 8.6 & 7 & 1.2 & 1 & 1.2 & 1 & 0.0 & 0 \\
\hline
\end{tabular}

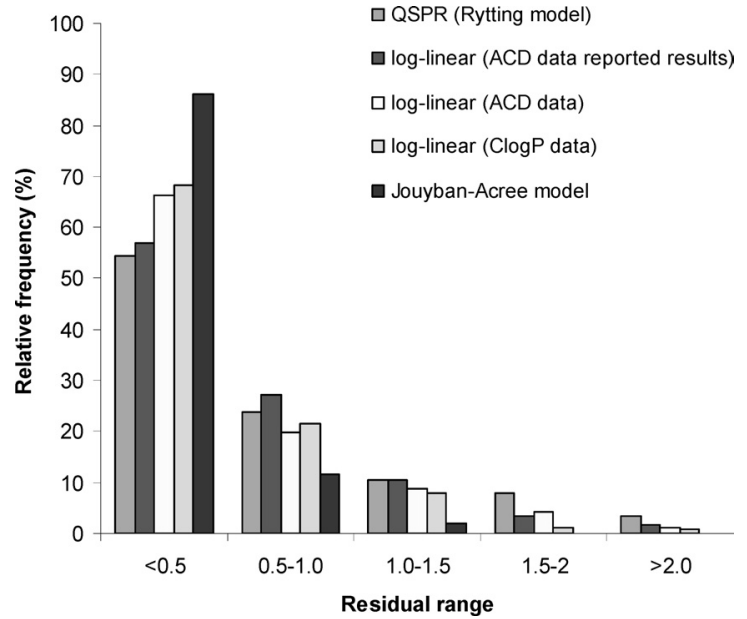

Fig. 1. Relative Frequency of Residuals (in log Units) for Predicted Solubilities in Water-PEG 400 Mixtures Using Various Numerical Methods

1. Solubility of the solute of interest in water and PEG 400 should be determined and used as input variables of the model.

2. The solvent composition of the mixed solvent system should be expressed as volume fraction $\left(f_{\mathrm{c}}\right.$ for volume fraction of PEG 400 and $f_{\mathrm{w}}$ for volume fraction of water).

3. Temperature should be expressed as absolute temperature $(\mathrm{K})$.

\section{Conclusion}

In conclusion, the proposed method provides more accurate predictions in comparison with previously established log-linear model of Yalkowsky and QSPR model of Rytting et al. The proposed method in this work employs one more datum in comparison with log-linear model, however, it does not require any more physico-chemical property like $\log P$. The prediction method is successfully extended to the various temperatures which are obviously required in drug for-

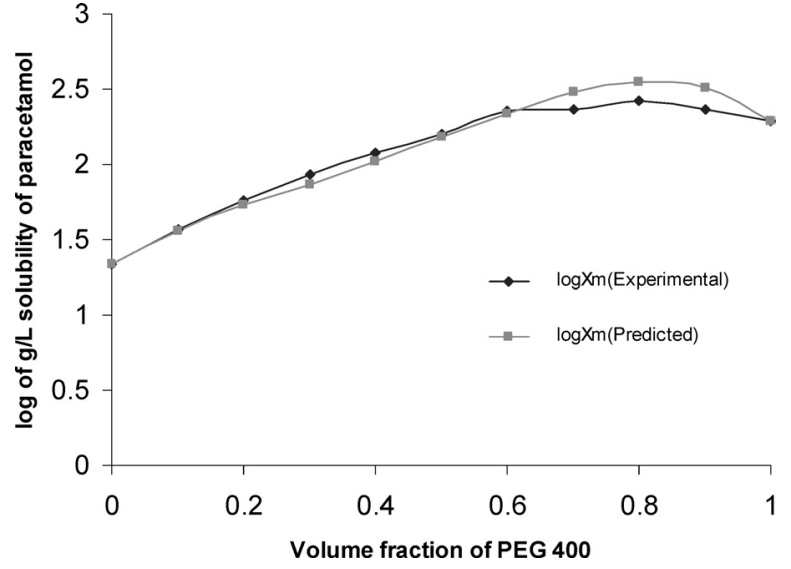

Fig. 2. Logarithm of Experimental Solubilities of Paracetamol in WaterPEG 400 Mixtures at $30^{\circ} \mathrm{C}$ Taken from a Reference ${ }^{14)}$ and the Predicted Values Using Eq. 10 versus Volume Fraction of PEG 400

mulation and also crystallization studies.

\section{References}

1) Yalkowsky S. H., Roseman T., "Solubilization of Drugs by Cosolvents," ed. by Yalkowsky S. H., Marcel Dekker, New York, 1981, pp. $91-134$

2) Martin A., Paruta A. N., Adjei A., J. Pharm. Sci., 70, 1115-1120 (1981).

3) Acree W. E., Thermochim. Acta, 198, 71-79 (1992).

4) Khoubnasabjafari M., Jouyban A., Acree W. E., Chem. Pharm. Bull., 53, 1591-1593 (2005).

5) Khossravi D., Connors K. A., J. Pharm. Sci., 81, 371-379 (1992).

6) Jouyban-Gharamaleki A., Chem. Pharm. Bull., 46, 1058-1061 (1998).

7) Barzegar-Jalali M., Jouyban-Gharamaleki A., Int. J. Pharm., 152, 247-250 (1997).

8) Ruckenstein E., Shulgin I., Int. J. Pharm., 260, 283-291 (2004).

9) Jouyban A., Chew N. Y. K., Chan H. K., Sabour M., Acree W. E., Chem. Pharm. Bull., 53, 634-637 (2005).

10) Strickley R. G., Pharm. Res., 21, 201-230 (2004)

11) Jouyban-Gharamaleki A., Valaee L., Barzegar-Jalali M., Clark B. J., 
Acree W. E., Int. J. Pharm., 177, 93-101 (1999).

12) Jouyban-Gharamaleki A., Acree W. E., Int. J. Pharm., 167, 177-182 (1998).

13) Rytting E., Lentz K. A., Chen X. Q., Qian F., Venkatesh S., AAPS J., 7, E78-E105 (2005).

14) Prakongpan S., Nagai T., Chem. Pharm. Bull., 32, 340-343 (1984).
15) Millard J. W., Alvarez-Nunez F. A., Yalkowsky S. H., Int. J. Pharm., 245, 153-166 (2002).

16) Rytting E., Lentz K. A., Chen X. Q., Qian F., Venkatesh S., Pharm. Res., 21, 237-244 (2004).

17) Machatha S. G., Yalkowsky S. H., Int. J. Pharm., 294, 185-192 (2005). 